[Agr. Biol. Chem., Vol. 34, No. 2, p. 248 256, 1970]

\title{
Studies on the Pungent Principle of Capsicum
}

\section{Part XIV Chemical Constitution of the Pungent Principle ${ }^{\dagger}$}

\author{
By Sadayoshi Kosuge and Masaji Furuta
}

\author{
Department of Agricultural Chemistry, Faculty of Agriculture, Gifu University \\ Received July 7, 1969
}

\begin{abstract}
The chemical constitutions of the pungent principle of Capsicum were investigated. These principles are assumed to consist of capsaicin, dihydrocapsaicin, nordihydrocapsaicin, homodihydrocapsaicin and two or more analogues of these materials. Thin-layer chromatography and open tubular gas chromatography showed that the natural pungent mixture contains no cis-isomer of capsaicin. The chemical structure of nordihydrocapsaicin was determined as $\mathrm{N}$-(4-hydroxy-3-methoxybenzyl)-7-methyloctanamide by gas chromatography, infrared spectroscopy, mass spectrometry and nuclear magnetic resonance spectroscopy. In addition, homodihydrocapsaicin was identified as $\mathrm{N}$-(4-hydroxy-3-methoxybenzyl)-9-methyldecaramide. These identities were also proven by comparison with synthetic samples.
\end{abstract}

Capsaicin, the pungent principle of Capsicum, was denoted as $\mathrm{N}$-(4-hydroxy-3-methoxybenzyl)-8-methylnon-trans-6-enamide by Nelson ${ }^{11}$ and Crombie et al. ${ }^{21}$ Kosuge et al. ${ }^{3 \prime}$ demonstrated the existence of saturated capsaicin (dihydrocapsaicin). Lately, Bennett et al." have suggested that the pungent principle is a mixture of at least five closely related vanillyl amides, which they named Capsaicin (mol. wt., 307-2) dihydrocapsaicin (307), nordihydrocapsaicin (307-14), homodihydrocapsaicin $(307+14)$, homocapsaicin $(307+14-2)$. In this paper, further investigation is made on the existence of the cis-isomer of capsaicin and the chemical structure of the homologues.

Crystalline pungent principles, isolated as described previously ${ }^{51}$ from the Japanese Capsicum, were separated by silver nitrate thin-layer chromatography into capsaicin $(R f$, $0.50)$, dihydrocapsaicin $(R f, 0.32)$ and two

+ Part of this work was presented at the meeting of the Chubu Division of the Agricultural Chemical Society of Japan held on November 31, 1968 at Nagoya, and at the Annual Meeting of the Society held in Tokyo, April, 2, 1969.

1) E. K. Nelson, J. Am. Chem. Soc., 45, 2179 (1923).

2) L. Crombie, S. H. Dandegaonker and K. S. Simpson, J. Chem. Soc., 1955, 1025. spots $(R f, 0.42,0.21)$. In thin-layer chromagraphy, no cis-capsaicin was detected in the natural pungent mixture. Methyl esters of fatty acids obtained from the natural mixture were analyzed by gas chromatography. In the gas chromatogram of the diethylene glycol succinate polyester (DEGS), Fig. 1, peak-3 and peak-4 were each identified as 8-methyl-nonanoate and 8-methylnon-trans-6-enoate by comparison with authentic samples. With the aid of published data, ${ }^{6}$ the relationship between logarithms of the retention volume relative to $n$-decanoate and the number of carbon atoms in the molecule from methyl esters of fatty acids led us to assume that the unknown peaks having ECL, equivalent carbon length, ${ }^{7}$ of 8.5 and the 10.5 on DEGS column are methyl esters of iso- $\mathrm{C}_{9}$ acid and iso- $\mathrm{C}_{11}$ acid, respectively. On the Apiezon M, peak- 4 and peak-3

3) S. Kosuge, Y. Inagaki and H. Okumura, Nippon Nogeikagaku Kaishi, 35, 923 (1961).

4) D. J. Bennett and G. W. Kirby, J. Chem. Soc., 1968, 442 .

5) S. Kosuge, Y. Inagaki and T. Uehara, Nippon Nogeikagaku Kaishi, 32, 578 (1957).

6) R. G. Ackman, J. Chromatog., 28, 225 (1967).

7) T. K. Miwa, J. Am. Oil Chemists' Soc., 40, 309 (1963). 

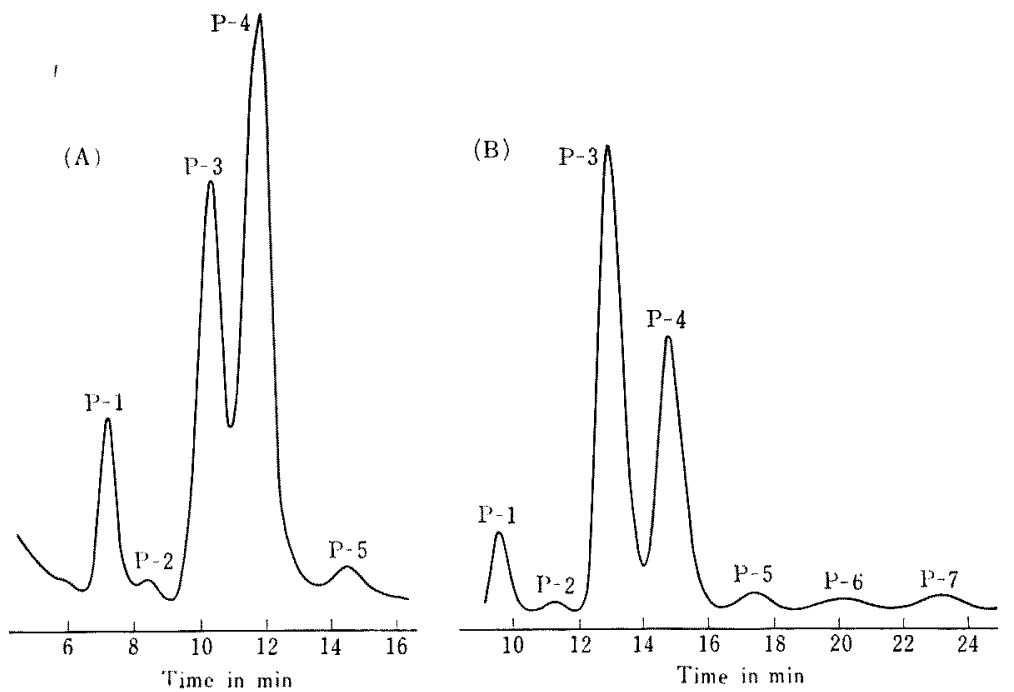

FIG. 1. Gas Chromatograms of Methyl Esters of the Fatty Acids from Capsicum.

Conditions (A): Column $3.5 \mathrm{~mm} \times 200 \mathrm{~cm}$, packing diethylene glycol succinate polyester 15\%; temp. $110^{\circ} \mathrm{C}, \mathrm{He}$ flow rate, $30 \mathrm{ml} / \mathrm{min}$.

Conditions (B): Column $3.5 \mathrm{~mm} \times 200 \mathrm{~cm}$, packing Apiezon grease $\mathrm{M} 25 \%$, temp. $160^{\circ} \mathrm{C}, \mathrm{He}$ flow rate, $35 \mathrm{ml} / \mathrm{min}$.

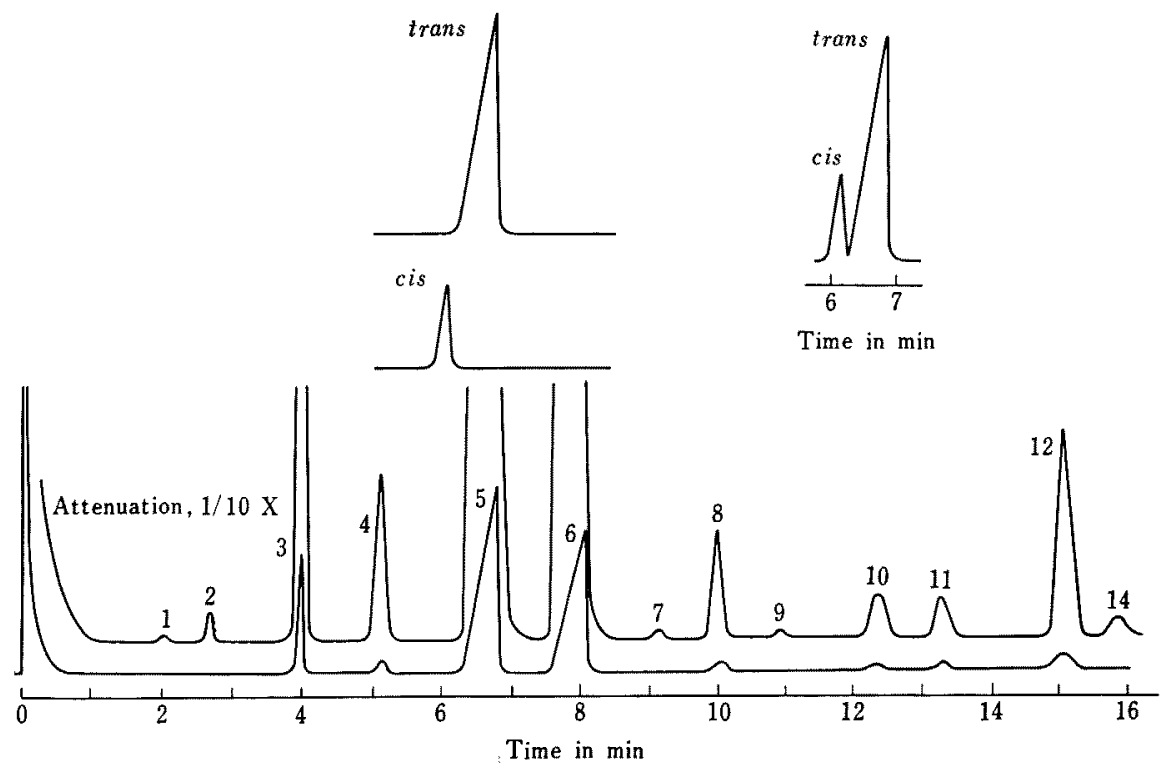

FIG. 2. Gas Chromatograms of Methyl Esters of the Fatty Acids from Capsicum.

Conditions: Golay column Q, (Apiezon grease L coated) $75 \mathrm{ft} \times 0.01$ inch i.d. operated at $100^{\circ} \mathrm{C}$ and 15 psig, He. Perkin-Elmer Model 226, No. 2 injection splitter, attenuation 1/100X. cis: Synthetic methyl 8-methylnon-cis-6-enoate; trans: Synthetic methyl 8-methylnon-trans-6-enoate. 
were identified as 8-methylnonanoate and 8methylnon-trans-6-enoate by the peak shift with hydrogenation and by comparison with authentic samples. Peak-1 and peak-7 on the Apiezon $M$ corresponded to peak-1 and peak-5 on the DEGS. The component of peak-1 had the same retention time as the synthesized 7-methyloctanoate. Likewise, peak-7 was identified as 9-methyldecanoate.

To investigate the existence of cis-isomer in the natural pungent mixture, gas chromatography of the fatty acid methyl ester obtained from a crystalline pungent mixture, was carried out using an open tubular column, Golay $Q$ (Fig. 2). The number of carbon atoms in each fatty acid was determined by comparison of their relative retention time in the gas chromatogram using a grid established under the same conditions as with known

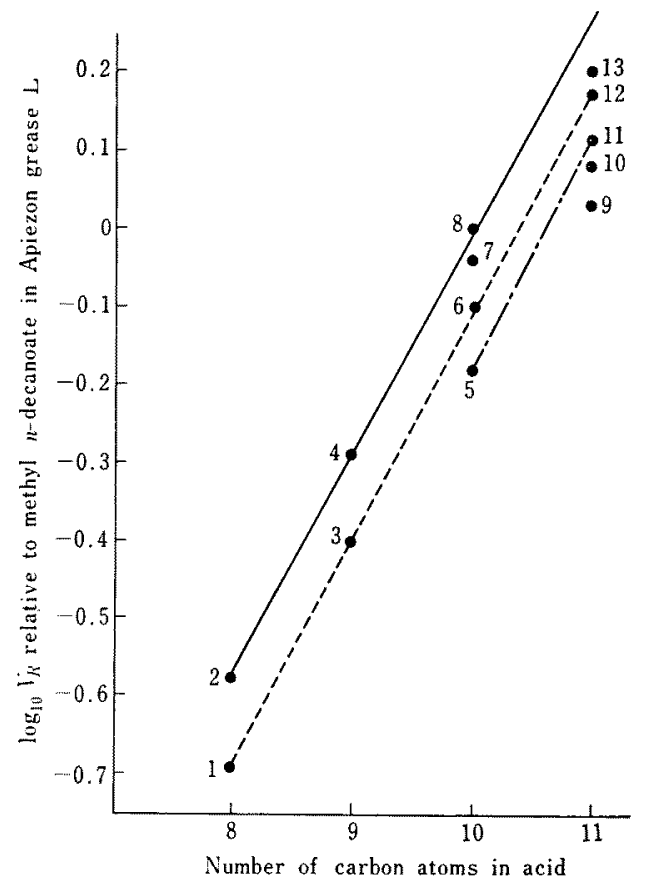

FiG. 3. Relationship between $\log _{10}$ of the $V_{R}$ Relam tive to Methyl Decanoate and the Number of Carbon Atoms in the Moleclues of the Esters.

-- straight-chain acids; ---o, iso acids; - mono-unsaturated iso acids. acids, Fig. 3. No isomerization between cisand trans-form occurred during the gas chromatography based on tests of authentic acid samples. The unknown peaks, 7, 9, 10 and 13, had ECL of 9.8, 10.1, 10.3 and 10.8, respectively. These results suggest that the cisisomer of capsaicin was not present in the natural material. In order to confirm the chemical structure of the iso acid, each component of the peaks was separated by preparative gas chromatography using a DEGS column. Infrared spectra of the isolated components were identical with those of the synthesized components. They had a doublet peak at $1380 \mathrm{~cm}^{-1}$, which suggests the presence of an isopropyl group. ${ }^{81}$ High resolution mass spectrometric studies offered further corroborating evidence for this postulation. The methyl ester of iso acid, containing a terminal isopropyl group, gives a mass spectrum that is similar to that of the normal chain isomer. The spectrum, however, contains a small peak at $m / e: \mathrm{M}^{+}-\left(\mathrm{CH}_{3} \mathrm{OH}+\mathrm{H}_{2} \mathrm{O}+\mathrm{CH}_{3}\right)$, which is absent in the normal chain isomer. The mass spectra of synthetic iso- $\mathrm{C}_{9}$ acid methylester and iso- $\mathrm{C}_{11}$ acid methyl ester had the same ion fragmentation patterns for the components of peak-1 and peak-5 (Figs. 4 and 5). In these mass spectra, the ketene ions m/e: M-47 were derived from the methoxycarbonyl type ions m/e: M-15 through loss of methanol. There were characteristic peaks of iso acid methyl ester at m/e: $\mathrm{M}^{+}-65$ arising through loss of water from the ketene ions. The peak at m/e: $\mathrm{M}^{+}-29$ which arises through loss of the ethyl group in normal fatty acid was, therefore, absent from these spectra. The result of NMR spectroscopy finally demonstrated the identity of the methyl esters isoloted with the authentic methyl esters. The characteristic peaks were the same as those of authentic samples of 7-methyloctanoate and

8) D. L. Guertin, S. E. Wiberley and W. H. Bauer, Anal. Chem., 28, 1194 (1956).

9) R. Ryhage and E. Stenhagen, Arkiv Kemi, 13, 523 (1959). 

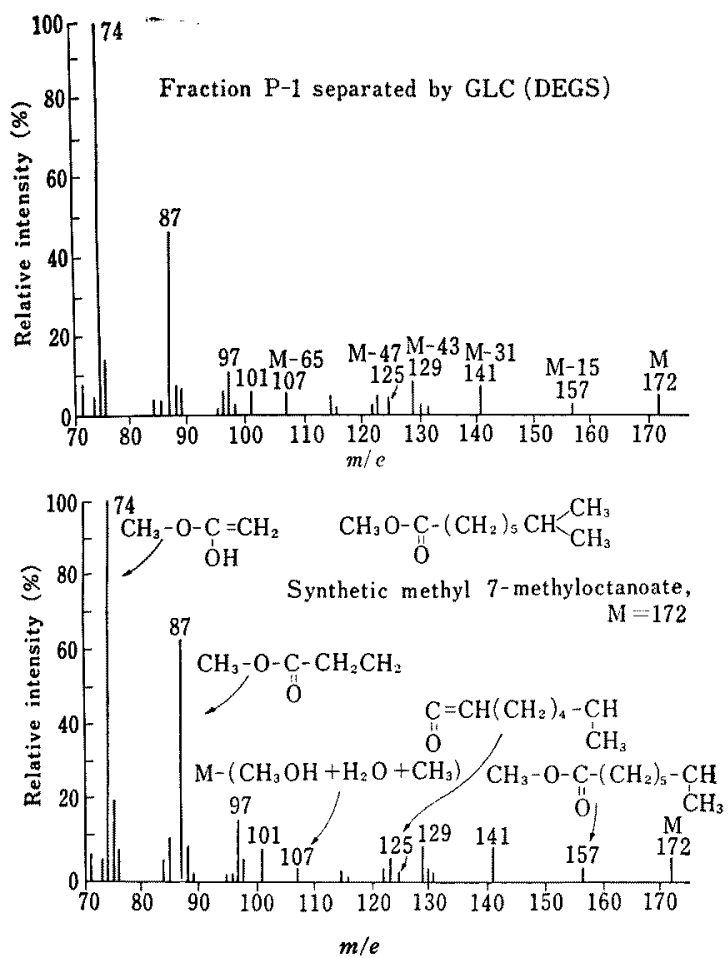

FIG. 4. Mass Spectra of Natural and Synthetic Methyl 7-Methyloctanoate.

9-methyldecanoate. The relative integral intensity of each signal and the assignments ${ }^{101}$ for peak-1 and peak-5 are shown in Table I. Thus, the identity of the isolated methyl esters with the authentic methyl esters was

TABle I. Chemical Shift Data for Isolated METHYLESTERS OF FATTY ACIDS

\begin{tabular}{lccc} 
& & \\
Chemical shift & peak-1 & peak -5 & Group \\
\hline 0.85 (doublet) & 6 & 6 & $\mathrm{CH}_{3}$ \\
1.20 (multiplet) & 9 & 13 & $\mathrm{CH}^{-\mathrm{CH}_{2}}$ \\
2.30 (triplet) & 2 & 2 & $\mathrm{CH}_{2}{ }^{a}$ \\
3.67 (singlet) & 3 & 3 & $\mathrm{OCH}_{3}$
\end{tabular}

a) Methylene group attached to the carbon atom carrying a carbomethoxy group.

10) T. Hashimoto, H. Shina and H. Mamuro, Kogyokagaku Zasshi, 68, 1434 (1965).
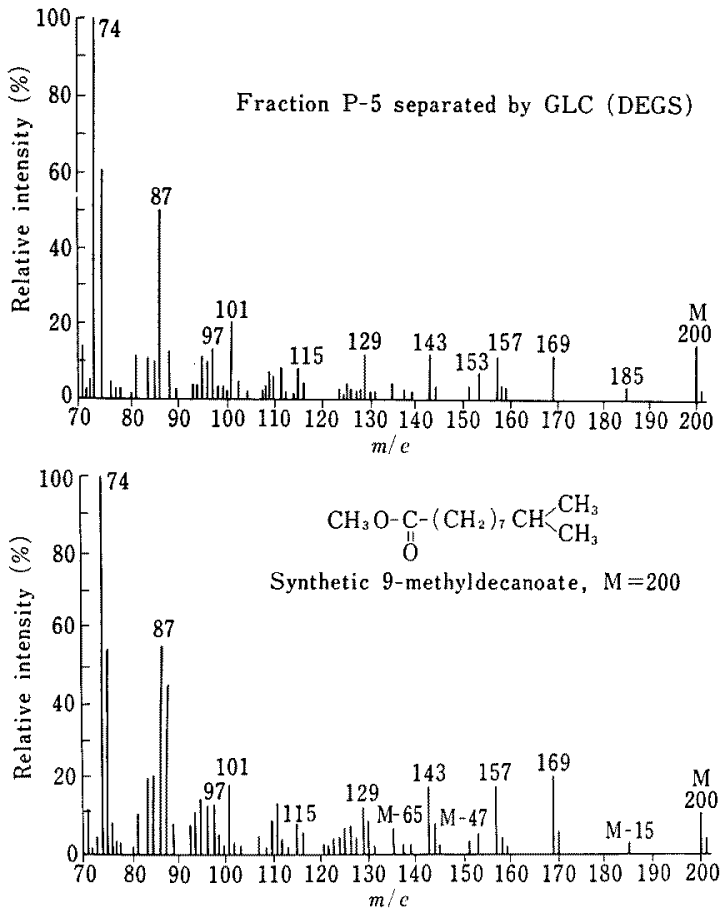

FIG. 5. Mass Spectra of Natural and Synthetic Methyl 9-Methyldecanoate.

confirmed by gas chromatography, and infrared, mass and nuclear magnetic resonance spectroscopy. The main conclusion is as follows.

Besides the reported 8-methylnonanoic acid and 8-methylnon-trans-6-enoic acid, 7-methyloctanoic and 9-methyldecanoic acid exist as the side chain fatty acids of the vanillyl amide, pungent principle of Capsicum. In order to clearly demonstrate this, vanillyl 7methyloctanamide (IIa) and vanillyl 9-methyldecanamide (IIb) were prepared from vanillyl amine and the authentic fatty acid chlorides respectively.

A thin-layer chromatogram on silica-gel impregnated with silver nitrate is shown in Fig. 6. $R f, 0.55$ and 0.27 components behaved as capsaicin and dihydrocapsaicin. $R f, 0.42$ and 0.14 components, respectively, were de- 


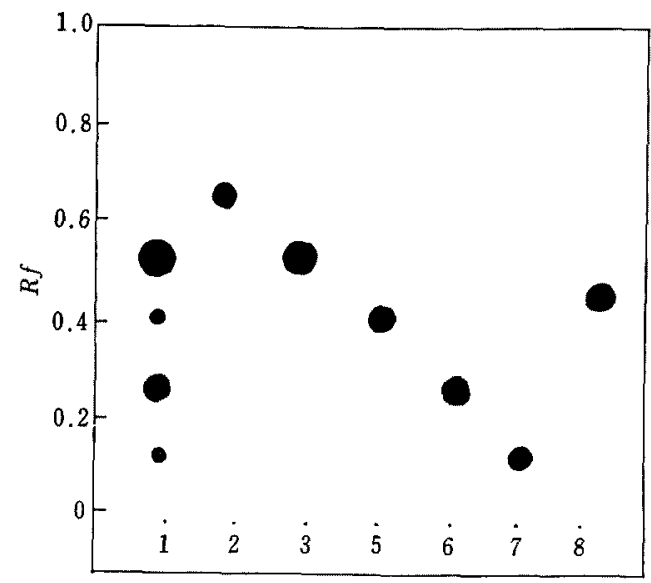

FIG. 6. Thin-layer Chromatogram of Pungent Principles.

Adsorbent: Silica-gel sheet impregnated with tetralin.

Solvent: $\mathrm{MeOH}$ : 2\%- $\mathrm{AgNO}_{3}(1: 1, \mathrm{v} / \mathrm{v})$.

Spray reagent: Folin-Ciocalteu's phenolic reagent.

Substrate: $\mathbf{l}=$ Crystalline pungent mixture of Capsicum; $2=$ cis Capsaicin; 3 =Capsaicin; $4=$ Nordihydrocapsaicin; $5=$ Dihydrocapsaicin; $6=$ Homodihydrocapsaicin; $7=n$-Nonoyl vanillylamide. (2, $3,4,5,6$ and 7 are synthetic compounds).

signated as the vanillyl 7 -methyloctanamide and vanillyl 9-methyldecanamide. Chromatographic identification was further confirmed by catalytic hydrogenation of the pungent mixture. In paper chromatography with $0.1 \mathrm{~N}$ sodium hydroxide as the solvent, capsaicinnordihydrocapsaicin and dihydrocapsaicinhomodihydrocapsaicin make critical pairs. To isolate the nordihydrocapsaicin from the natural pungent mixture, catalytic hydrogenation was carried out with the pungent mixture to convert capsaicin into dihydrocapsaicin. The saturated sample was applied to filter paper for chromatography and developed by $0.1 \mathrm{~N}$ sodium hydroxide. The eluted component $(R f, 0.45)$ by $0.1 \mathrm{~N}$ sodium hydroxide refined and recrystalized with petroleum ether (bp $40 \sim 60^{\circ} \mathrm{C}$ ). The infrared spectrum of the purified crystalline pungent mixture was identical with that of authentic vanillyl 7methyloctanamide, as shown in Fig. 7. The infrared spectrum suggests the presence of a phenolic hydroxy group peak in the $\mathrm{OH}$ stretching frequency region at $3550 \mathrm{~cm}^{-1} \sim$ $3420 \mathrm{~cm}^{-1}$ The characteristic peak of the secondary amide appeared at about $1630 \mathrm{~cm}^{-1}$. In UV spectra the purified product showed a large peak at $281 \mathrm{~m} \mu$ in ethyl alcohol. The UV spectrum of the isolated pungent mixture was identical with that of synthesized one. The NMR spectrum of isolated nordihydrocapsaicin was measured before and after $\mathrm{D}_{2} \mathrm{O}$ exchange, as shown in Fig. 8.

The NMR spectrum showed signals at 0.90 ppm due to gem-dimethyl protons, at 1.20 $\mathrm{ppm} \sim 1.80 \mathrm{ppm}$ and $2.20 \mathrm{ppm}$ due to methyne and methylene protons, at $3.80 \mathrm{ppm}$ due to methyl protons of methoxy group and at 6.75 ppm due to aryl protons. The two signals shown at $6.0 \mathrm{ppm}$ and $6.35 \mathrm{ppm}$, which were removable by addition of $\mathrm{D}_{2} \mathrm{O}$, were assigned respectively to protons of the phenolic hydroxyl group and the NH group. The doublet at $4.25 \mathrm{ppm}$ due to benzyl protons collapsed

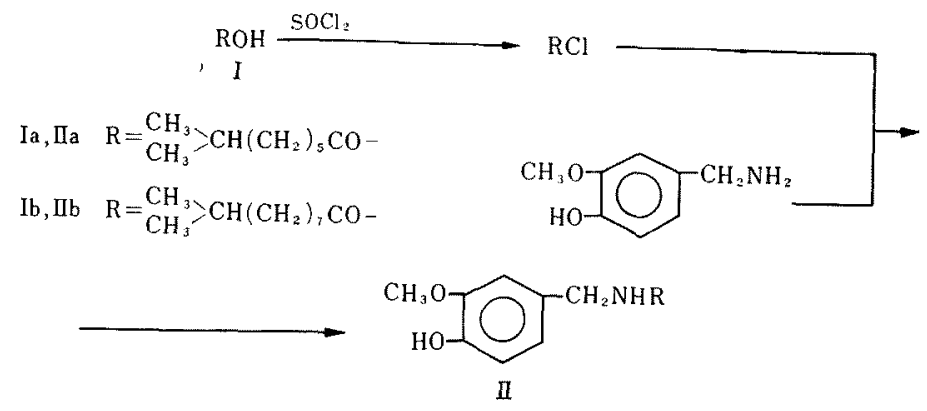




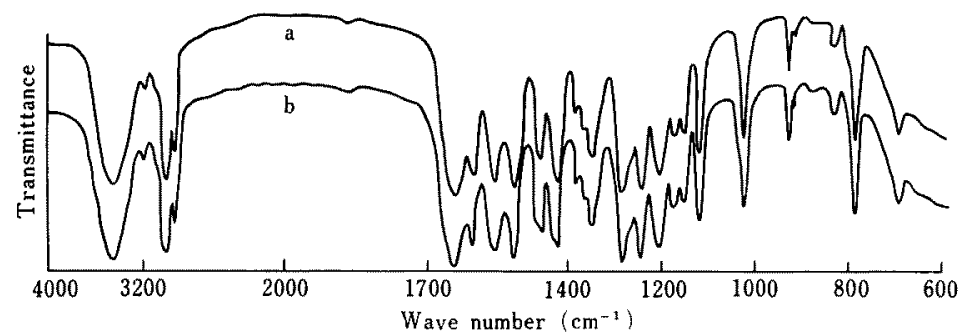

Frg. 7. Infrared Spectra of Natural and Synthetic Nordihydrocapsaicin.

$a=$ Synthetic nordihydrocapsaicin, $b=$ Pungent principle isolated from a crystalline pungent mixture of Capsicum. (KBr).

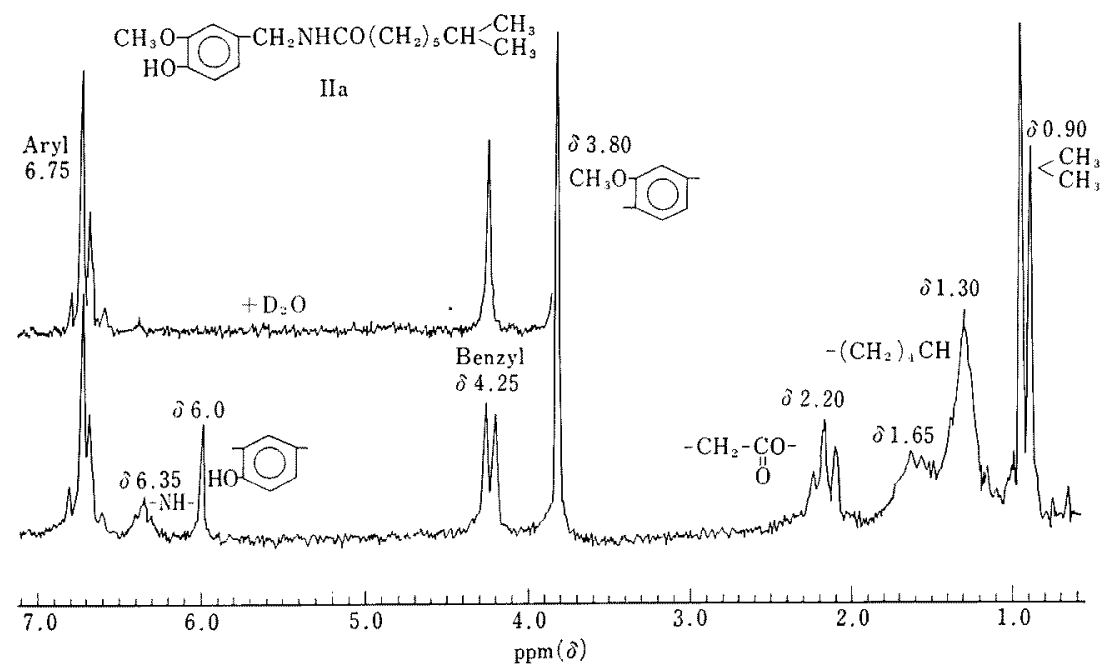

FIG. 8. 100-MHz NMR Spectrum of Natural Nordihydrocapsaicin in the Range of $80.6 \sim 7.1 \mathrm{ppm}$.

Solvent: $\mathrm{CDCl}_{3}$, Standard: $\mathrm{Me}_{4} \mathrm{Si}$.

to a singlet after treatment with $\mathrm{D}_{2} \mathrm{O}$.

Isolation of homodihydrocapsaicin from the natural pungent mixture is difficult because of its scarceness and because of the formation of the critical pair with dihydrocapsaicin. Attempts to separate homodihydrocapsaicin from the pungent mixture were unsuccessful. Accurate mass measurements of the natural crystalline pungent mixture and isolated fatty acids are presented in Table II. The mass spectrum of the authentic pungent principle showed no $\mathrm{M}^{+} \pm \mathrm{CH}_{2}$ peaks. Therefore, the peaks at m/e: $184(170+14)$, $198(170+14 \times 2)$ and $200(186+14)$ suggest the presence of homologues of the principal components. It was necessary to consider the possibility of the formation of these homologues in the course of isolating the pungent principles from natural Capsicum. To clarify this, thin-layer chromatography was carried out on silica-gel impregnated with a silver nitrate of acetone extract of seed pods of Capsicum. The chromatogram gave four distinct pungent spots. It is also possible that the formation of the homologues of fatty acids occur during decomposition of the crystalline pungent mixture. But gas chromatograms of fatty acid methyl esters, which were obtained 
Table II. Accurate Mass Measurements

\begin{tabular}{|c|c|c|c|}
\hline Compound & Found & Calculated & $\begin{array}{l}\text { Molecular } \\
\text { formula }\end{array}$ \\
\hline \multirow{5}{*}{$\begin{array}{l}\text { Pungent mixture } \\
\text { of Capsicum }\end{array}$} & 293.198 & 293.199 & $\mathrm{C}_{17} \mathrm{H}_{27} \mathrm{NO}_{3}$ \\
\hline & 305.204 & 305.199 & $\mathrm{C}_{18} \mathrm{H}_{27} \mathrm{NO}_{3}$ \\
\hline & 307.220 & 307.215 & $\mathrm{C}_{18} \mathrm{H}_{29} \mathrm{NO}_{3}$ \\
\hline & 319.212 & 319.215 & $\mathrm{C}_{19} \mathrm{H}_{29} \mathrm{NO}_{3}$ \\
\hline & 321.223 & 321.230 & $\mathrm{C}_{19} \mathrm{H}_{31} \mathrm{NO}_{3}$ \\
\hline \multirow{7}{*}{$\begin{array}{l}\text { Fatty acids } \\
\text { from pungent } \\
\text { mixture }\end{array}$} & 158.128 & 158.131 & $\mathrm{C}_{9} \mathrm{H}_{18} \mathrm{O}_{2}$ \\
\hline & 170.130 & 170.131 & $\mathrm{C}_{10} \mathrm{H}_{18} \mathrm{O}_{2}$ \\
\hline & 172.144 & 172,146 & $\mathrm{C}_{10} \mathrm{H}_{20} \mathrm{O}_{2}$ \\
\hline & $\{184.144$ & 184.146 & $\mathrm{C}_{11} \mathrm{H}_{20} \mathrm{O}_{2}$ \\
\hline & 186.158 & 186.162 & $\mathrm{C}_{11} \mathrm{H}_{22} \mathrm{O}_{2}$ \\
\hline & 198.160 & 198.162 & $\mathrm{C}_{12} \mathrm{H}_{22} \mathrm{O}_{2}$ \\
\hline & 200.176 & 200.178 & $\mathrm{C}_{12} \mathrm{H}_{24} \mathrm{O}_{2}$ \\
\hline
\end{tabular}

from the authentic pungent principle by decomposition, showed no homologues peaks. This indicates that the formation of homologues does not occur in the course of decomposition. These results prove the existence of homologues in the natural pungent mixture. Infrared spectroscopy, mass spectroscopy and thin-layer chromatography of vanillyl residue isolated from natural crystalline pungent mixture confirmed that there are no homologues with varying vanillyl residue. The relative amounts of pungent principle were calculated from the densitometry of thin-layer chromatograms with silver nitrate-silica-gel, the intensities of the molecular ion peaks in the mass spectrum of the crystalline pungent mixture, and the intensities of peaks in the gas chromatograms of fatty acids isolated from the pungent mixture. The resulting approximate composition is capsaicin (48.6\%), dihydrocapsaicin (36.0\%), nordihydrocapsiacin $(7.4 \%)$, homodihydrocapsaicin (2.0\%), homocapsaicin (2.0\%), nonoyl vanillylamide $(1.0 \%)$ and decoyl vanillylamide (1.5\%).

\section{EXPERIMENTAL}

All melting points were determined on a Yanagimoto micromelting point apparatus and were cor- rected. Infrared spectral data were obtained with a JASCO (Japan Spectroscopic Co., Ltd.) DS-301 spectrophotometer. Ultraviolet spectra were obtained with a Shimazu AQV-50 spectrophotometer. NMR were recorded with a Varian HA-100 spectrometer at 100-Mc and a Varian $\mathrm{A}-60 \mathrm{D}$ spectrometer at $60 \mathrm{Mc}$ in deuterochloroform using tetramethylsilane as an internal reference. MS spectra were measured with a CEC$110 \mathrm{~B}$ double focusing spectrometer using an ionization potential of $70 \mathrm{eV}$. In mass spectrometry, methyl esters of the fatty acids were introduced through a heated inlet system at 140 to $150^{\circ} \mathrm{C}$. The pungent principles were introduced by direct insertion on a probe at $90^{\circ} \mathrm{C}$; ion source temperature $115^{\circ} \mathrm{C}$. Scanning graphs of thin-layer chromatograms were obtained with an OZUMOR-82 densitometer. Gas chromatography was carried out with a Yanagimoto GCG-5DH equipped with a thermal conductivity detector and an automatic preparative attachment. Open tubular gas chromatography was carried out with a Perkin Elmer model 226 equipped with a flame ionization detector.

Isolation of fatty acids. Seven grams of the pungent mixture ( $\mathrm{mp} 64.5^{\circ} \mathrm{C}$ ) was decomposed as described previously. ${ }^{3)}$ Carbon dioxide gas was bubbled through the resulting aqueous solution. The phenolic compounds were removed by ether extraction. The waterlayer was acidified with dilute sulfuric acid and extracted with ether. Then the organic layer was washed with water and dried. The residue remaining after removal of ether was distilled. Bp 137 $142^{\circ} \mathrm{C} / 18 \mathrm{~mm}$, Yield from pungent mixture, $3.03 \mathrm{~g}$ (77\%). $\quad n_{\mathrm{D}}^{20} 1.4380 . \quad$ IR $\nu_{\max }^{\mathrm{NaCl}} \mathrm{cm}^{-1}: \quad 3000 \sim 2500,1707$, 1462, 1410, 1385, 1365, 1290, 1235, 1115, 968, 937. The MS data in Table II and the methylated fatty acids were analyzed by gas chromatography, as shown in Figs. 1 and 2.

Gas chromatography. Methyl esters of the fatty acids were prepared by the method reported by Schlenk et al.11) The columns were $3.5 \mathrm{~mm} \times 200 \mathrm{~cm}$ U-shape stainless steels packed with $15 \mathrm{w} / \mathrm{w} \%$-DEGS coated on $80 \sim 100$-mesh Celite 545 or with $25 \mathrm{w} / \mathrm{w} \%$-Apiezon grease $M$ coated on $40 \sim 60$ mesh Fire-brick C-22. The open tubular column (Golay Q), Apiezon grease $L$ coated, $75 \mathrm{ft}$ in length and 0.01 inch $i . d$., was purchased from Perkin Elmer. In preparative gas

11) H. Schlenk and J. L. Gellerman, Anal. Chem., $32,1412(1960)$. 
chromatography, stainless steel columns, $400 \mathrm{~cm}$ in length and $1.4 \mathrm{~cm} i . d$, were packed with $15 \mathrm{w} / \mathrm{w} \%$ DEGS.

Syntheses of fatty acids and pungent principles.

A) 7-Methyl octanoic acid (Ia). Grignard solution prepared in the usual way ${ }^{12}$ from $50 \mathrm{~g}$ of isoamyl bromide and $8.1 \mathrm{~g}$ of magnesium was cooled in ice and $33 \mathrm{~g}$ of dried cadmium chloride was added. A solution of $40 \mathrm{~g}$ of $\beta$-carbomethoxypropionyl chloride in ether was added to the ether solution of organocadmium compound in about $5 \mathrm{~min}$. The solution was stirred for $45 \mathrm{~min}$ at room temperature and for an additional hour with refluxing. After decomposition with ice and sulfuric acid, the ether layer was washed with $5 \%$ sodium carbonate solution and with water, then dried and distilled. The ketoester was collected at bp $100 \sim 105^{\circ} \mathrm{C} / 10 \mathrm{~mm}$. Yield, $15.5 \mathrm{~g}$ (32\%).

Fifteen grams of the ketoester was reduced using the Clemmenson procedure ${ }^{13}$ with $50 \mathrm{~g}$ of amalgamated zinc, $40 \mathrm{ml}$ of water, and $100 \mathrm{ml}$ of concentrated hydrochloric acid. Refluxing was continued for $46 \mathrm{hr}$, during which time $170 \mathrm{ml}$ of concentrated hydrochloric acid and a $25 \mathrm{~g}$ charge of amalgamated zinc were added. The colorless product was extracted with hexane, and after this extract had been washed and dried, the acid was distilled. Bp $121 \sim 123^{\circ} \mathrm{C} / 15$ $\mathrm{mm}$. Yield from the ketoester, $8.7 \mathrm{~g}(68 \%) \cdot \bar{n}_{\mathrm{D}}^{20} 1.4332$. $d^{20} 0.9245$. Anal. Found: C, 68.51; H, 11.91. Calcd. for $\mathrm{C}_{9} \mathrm{H}_{18} \mathrm{O}_{2}: \mathrm{C}, 68.40 ; \mathrm{H}, 11.47$. IR $\mathrm{L}_{\max }^{\mathrm{NaCl}} \mathrm{cm}^{-1}: 3000 \sim$ $2500,1702,1465,1412,1385,1365,1280,1232,1165$, $1110,930,720$. Methylester's $\mathrm{NMR} \delta_{\mathrm{Me}_{4} \mathrm{Si}}^{\mathrm{CDCl}_{3}} ; 0.85$ $\left(6 \mathrm{H}\right.$, doublet, $\left.\mathrm{gem}-\mathrm{CH}_{3}\right), 1.20 \sim 1.85$ ( $9 \mathrm{H}$, multiplet, $\left.-\left(\mathrm{CH}_{2}\right)_{4} \mathrm{CHMe}_{2}\right), 2.30\left(2 \mathrm{H}\right.$, triplet, $\left.-\mathrm{CH}_{2} \mathrm{CO}-\right), 3.67$ (3H, singlet, $-\mathrm{OCH}_{3}$ ). Amide, mp $106^{\circ} \mathrm{C}$ (lit., $\left.{ }^{14}\right)$ $106.5^{\circ} \mathrm{C}$ ). MS spectrum of the methylester is shown in Fig. 4.

B) N-(4-Hydroxy-3-methoxybenzyl)-7-methyloctanamide (IIa). Three milliliters of thionyl chloride was added to a solution of $0.7 \mathrm{~g}$ of 7 -methyloctanoic acid in $5 \mathrm{ml}$ absolute ether, and the solution was set aside for $18 \mathrm{hr}$ at room temperature. It was then heated at $100^{\circ} \mathrm{C}$ for $1 \mathrm{hr}$ and excess reagent was removed under reduced pressure. The residual acid chloride was

12) A. H. Blatt, "Organic Syntheses," Coll. Vol. I, 2nd ed., John Wiley and Sons, Inc., 1956, p. 75.

13) E. L. Martin, J. Am. Chem. Soc., 58138 (1936).

14) P. A. Levene and C. H. Allen, J. Biol. Chem., 27, 433 (1916). added to $1.4 \mathrm{~g}$ of freshly prepared vanillyl amine suspended in $50 \mathrm{ml}$ of ether. This mixture was shaken for 3 days, then poured into water and extracted. Extracts were dried and evaporated producing $0.67 \mathrm{~g}$ of crude amide, which crystallized from light petroleum (bp $40 \sim 60^{\circ} \mathrm{C}$ ). $\mathrm{Mp}_{\mathrm{p}} 65.6^{\circ} \mathrm{C}$, Yield, $0.41 \mathrm{~g} \mathrm{(16 \% ).} \mathrm{Anal.} \mathrm{Found:} \mathrm{C,} \mathrm{69.15;} \mathrm{H,} \mathrm{9.45;} \mathrm{N,}$ 4.74. Calcd. for $\mathrm{C}_{17} \mathrm{H}_{27} \mathrm{NO}_{3}$ : C, $69.59 ; \mathrm{H}, 9.28 ; \mathrm{N}$, 4.77. $\mathrm{UV} \lambda_{\max }^{\mathrm{E} 1 \mathrm{H}} \mathrm{m} \mu: 281 . \quad \mathrm{MS} m / e: 293\left(\mathrm{M}^{+}\right), 195$ $\left(\mathrm{C}_{10} \mathrm{H}_{13} \mathrm{NO}_{3}+\right), 137\left(\mathrm{C}_{8} \mathrm{H}_{9} \mathrm{O}_{2}{ }^{+}\right.$, base peak). $\mathrm{NMR} \delta_{\mathrm{Me}_{4} \mathrm{Si}}^{\mathrm{CDCl}_{3}}$ $0.90\left(6 \mathrm{H}\right.$, doublet, gem- $\left.\mathrm{CH}_{3}\right), 1.20 \sim 1.85(9 \mathrm{H}$, multiplet, $\left.-\left(\mathrm{CH}_{2}\right)_{4} \mathrm{CHMe}_{2}\right), 2.30\left(2 \mathrm{H}\right.$, triplet, $\left.-\mathrm{CH}_{2} \mathrm{CO}-\right)$, $3.80\left(3 \mathrm{H}\right.$, singlet, $\left.-\mathrm{OCH}_{3}\right), 4.20(2 \mathrm{H}$, doublet, benzyl), $6.0(1 \mathrm{H}$, singlet, $-\mathrm{OH}), 6.34(1 \mathrm{H}$, multiplet, $-\mathrm{NH}-)$, $6.70(3 \mathrm{H}$, multiplet, aryl). The IR spectrum is shown in Fig. 7.

C) 9-Methyldecanoic acid (Ib). 9-Methyldecanoic acid was prepared, by the same method as for Ia, from $38 \mathrm{~g}$ of methyl 6-keto-9-methyldecanoate which was obtained from di-isoamyl cadmium and $\delta$-carbomethoxyvaleryl chloride in benzene. Bp $127 \sim 129^{\circ} \mathrm{C}$ / $2.5 \mathrm{~mm}$. Yield, $16.6 \mathrm{~g} \mathrm{(50.3 \% )}$. Anal. Found: C, 71.24; H, 12.18. Calcd. for $\mathrm{C}_{11} \mathrm{H}_{22} \mathrm{O}_{2}: \mathrm{C}, 70.92 ; \mathrm{H}$,

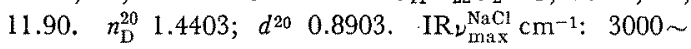
$2500,1705,1463,1408,1383,1365,1285,1165,1110,935$, 720. Methylester's $\mathrm{NMR} \delta_{\mathrm{Me}_{4} \mathrm{Si}}^{\mathrm{CDCl}_{3}} \cdot 0.85(6 \mathrm{H}$, doublet, gem- $\left.\mathrm{CH}_{3}\right), 1.20 \sim 1.85\left(13 \mathrm{H}\right.$, multiplet, $\left.-\left(\mathrm{CH}_{2}\right)_{6} \mathrm{CHMe}_{2}\right)$, $2.30\left(2 \mathrm{H}\right.$, triplet, $\left.-\mathrm{CH}_{2} \mathrm{CO}-\right), 3.67(3 \mathrm{H}$, singlet, $-\mathrm{OCH}_{3}$ ). $p$-Bromophenacyl ester, $\mathrm{mp} 65.0^{\circ} \mathrm{C}$ (lit., ${ }^{15}$ ) $65.5^{\circ} \mathrm{C}$ ). The MS spectrum of the methylester is shown in Fig. 5.

D) $N$-(4-Hydroxy-3-methoxybenzyl)-9-methyldecanamide (IIb). The amide (IIb) was obtained by the method described for Ila from $1.2 \mathrm{~g}$ of 9-methyldecanoic acid chloride and $1.3 \mathrm{~g}$ of vanillyl amine. $\mathrm{Mp} 66.5^{\circ} \mathrm{C}$. Yield, $0.47 \mathrm{~g}$ (21\%). Anal. Found: C, 70.84; H, 9.80; $\mathrm{N}, 4.40$. Calcd. for $\mathrm{C}_{19} \mathrm{H}_{31} \mathrm{NO}_{3}: \mathrm{C}, 70.99 ; \mathrm{H}, 9.72$, $\mathrm{N}, 4.36 . \mathrm{UV} \lambda_{\max }^{\mathrm{EtOH}} \mathrm{m} \mu: 280.5 . \quad \mathrm{IR}_{\nu_{\mathrm{max}}}^{\mathrm{KBr}} \mathrm{cm}^{-1}: 3440$, $2930,1628,1512,1415,1348,1284,1205,1120,1030$, 804. MS m/e: $321\left(\mathrm{M}^{+}\right), \quad 195\left(\mathrm{C}_{10} \mathrm{H}_{13} \mathrm{NO}_{3}{ }^{+}\right), 137$ $\left(\mathrm{C}_{8} \mathrm{H}_{9} \mathrm{O}_{2}{ }^{+}\right) . \mathrm{NMR}_{\mathrm{Me}_{4} \mathrm{Si}}^{\mathrm{CDCl}_{3}}: 0.85\left(6 \mathrm{H}\right.$, doublet, gem- $\left.\mathrm{CH}_{3}\right)$, $1.20 \sim 1.85\left(13 \mathrm{H}_{3}-\left(\mathrm{CH}_{2}\right) \mathrm{CHMe}_{2}\right), 2.30(2 \mathrm{H}$, triplet, $\left.-\mathrm{CH}_{2} \mathrm{CO}-\right), 3.80\left(3 \mathrm{H}\right.$, singlet, $\left.-\mathrm{OCH}_{3}\right), 4.20(2 \mathrm{H}$, doublet, benzyl), $5.75(1 \mathrm{H}$, singlet, $-\mathrm{OH}), 6.20(1 \mathrm{H}$, multiplet, $-\mathrm{NH}-), 6.70(3 \mathrm{H}$, multiplet, aryl).

Isolation of IIa from the pungent mixture of Capsicum.

15) C. V. Wilson, J. Am. Chem. Soc., 67, 2161 (1945). 
Catalytic hydrogenation was done on the pungent mixture isolated from Capsicum using Raney $\mathrm{Ni}$ $\mathrm{W}-6^{16)}$ as the catalyst. The hydrogenated pungent mixture was developed with $0.1 \mathrm{~N}$ sodium hydroxide as solvent for the paper chromatography. Spots of the pungent principles were observed on the paper chromatogram without using a color-producing reagent. The component of the spot $R f, 0.42$ was extracted with $0.1 \mathrm{~N}$ sodium hydroxide. The collected alkaline aqueous solution was treated with sodium hydrocarbonate, then shaken with ether. The organic layer which separated, was washed with water and

16) A. H. Blatt, "Organic Syntheses," Coll. Vol. III, 2nd ed., John Wiley and Sons, Inc., 1956, p. 181. dried. After removal of the solvent, the residue was recrystallized with petroleum ether (bp $40 \sim 60^{\circ} \mathrm{C}$ ). Forty-four $\mathrm{mg}$ of the crystalline pungent principle was obtained from $2 \mathrm{~g}$ of the pungent mixture. $\mathrm{Mp}$ $64.5^{\circ} \mathrm{C}$. MS m/e: $293.194\left(\mathrm{M}^{+}\right.$, calcd. for $\mathrm{C}_{17} \mathrm{H}_{27} \mathrm{NO}_{3}$, 293.199), $195\left(\mathrm{C}_{10} \mathrm{H}_{13} \mathrm{NO}_{3}{ }^{+}\right.$, base peak). Synthetic IIa gave the same ion fragment pattern. IR and NMR data are in the text.

Acknowledgements. The authors wish to express their thanks to Dr. A. Hasegawa and Mr. S. Sawada, of Kyoto University, for NMR spectra measurement and elemental analyses. We are also indebted to Dr. N. Wasada, Government Chemical Industrial Research Institute, Tokyo, for the high resolution mass spectra measurements. 